\title{
Accuracy of estimating age from eruption levels of mandibular teeth
}

\author{
Sheryl E. Wilmott ${ }^{1}$, Mark P. Hector ${ }^{2}$, Helen M. Liversidge ${ }^{1}$ \\ 1 Queen Mary University of London, Barts and The London School of Medicine and Dentistry, Institute of Den- \\ tistry, Turner Street, London, United Kingdom E1 2AD. 2 School of Dentistry, University of Dundee \\ Park Place, Dundee, Scotland, DD1 4HN
}

Keywords: Age Estimation, Alveolar Eruption, Permanent Teeth

ABSTRACT Little is documented on the accuracy of estimating age from alveolar eruption (AE) or partial eruption (PE). The aim of this study was to compare the accuracy of age estimation from eruption levels. Methods tested were Gleiser and Hunt (1955), Garn et al. (1958), Ando et al. (1965), Haavikko (1970) and clinical eruption from Smith et al. (1998). The sample was 946 panoramic dental radiographs from children aged 3-16 years. Left mandibular teeth (excluding third molar) were assessed for eruption level (AE and PE) and root quarters. Methods, teeth and eruption levels were deemed to be accurate if the average difference

An 1837 pamphlet by Saunders entitled "The Teeth: a Test of Age" (considered with reference to the factory children) was one of the earliest uses of age estimation from eruption of teeth (Miles 1963). This stated that if the third molar was present in the mouth (i.e. the first permanent molar M1, behind the deciduous molars), the child was likely to be 9 years of age.

The accuracy of estimating age from tooth formation has been well documented, however, the accuracy of estimating age from alveolar or partly erupted or the clinical presence of a tooth in the oral cavity is unknown. Estimating age from a partially erupted tooth is useful if root stage cannot be visualised or has been damaged. The aim of this study was to assess the accuracy of estimated age using several methods that provide mean/median age of tooth eruption levels.

\section{MATERIAL AND METHODS}

The sample was panoramic dental radiographs of 946 healthy children of known age attending a dental teaching hospital. Subjects include at least 30 boys and 30 girls of each year of age from 3 to 16 (489 boys, 457 girls, mean age 9.80, age 3.00-16.99). Each year age group was made up similar numbers of children from Bangla- between estimated and chronological ages was not significant to zero using a $t$-test $(\mathrm{P}>0.05)$. Results show that early erupting permanent teeth were fairly good at estimating age, although there was considerable age variation in eruption. Haavikko incisors and molars at $\mathrm{AE}$ and Haavikko and Smith central incisor and second molar at PE estimated age accurately. Root stage of erupting teeth estimated age more accurately than eruption level using Haavikko. These findings suggest that erupting permanent mandibular teeth can be helpful in estimating age.

deshi and white ethnic origin. Panoramic radiographs were taken with consent in the course of diagnosis and treatment in Paediatric Dentistry and Orthodontics. This is the same sample used to test dental age estimation methods by Maber et al. (2006), Liversidge et al. (2010) and AlQahtani et al. (2014).

Eruption levels of seven mandibular teeth (excluding the third molar) on the left side were assessed by the first author. Eruption levels were defined as developing tooth within bone, cusp tips at or just above the alveolar bone level (AE), cusp tips considerably above the alveolar bone level but not fully erupted (PE), fully erupted. Eruption levels and root fractions are illustrated in Figure 1. Intra-observer reliability of assessing eruption level was calculated from duplicate scoring of 20 radiographs (140 teeth) yielding a Kappa value of 0.96. Tooth formation of seven mandibular teeth on the left side were assessed using tooth stages of Moorrees et al. (1963) as part of a previous study (Maber et al., 2006).

Correspondence to: Dr. Helen Liversidge

Institute of Dentistry

Turner Street, London, United Kingdom E1 2AD

Email: h.m.liversidge@qmul.ac.uk 
The number of erupting teeth (AE and/or PE) on the left side of the mandible within an individual was counted.

Age was estimated if a tooth was at $\mathrm{AE}$ or $\mathrm{PE}$, using Glesier and Hunt (1955), Garn et al. (1958), Ando et al. (1965) and Haavikko (1970). If a tooth was partially erupted, age was also estimated from Haavikko (1970) and Smith et al. (1998). These values are shown in Table 1. Values for Ando et al. (1965) were calculated in Liversidge (2003) and contain an error M1 in boys. The raw data show that $60 \%$ of the youngest age category had reached AE.

Chronological age was subtracted from estimated age by tooth type and eruption level and the difference
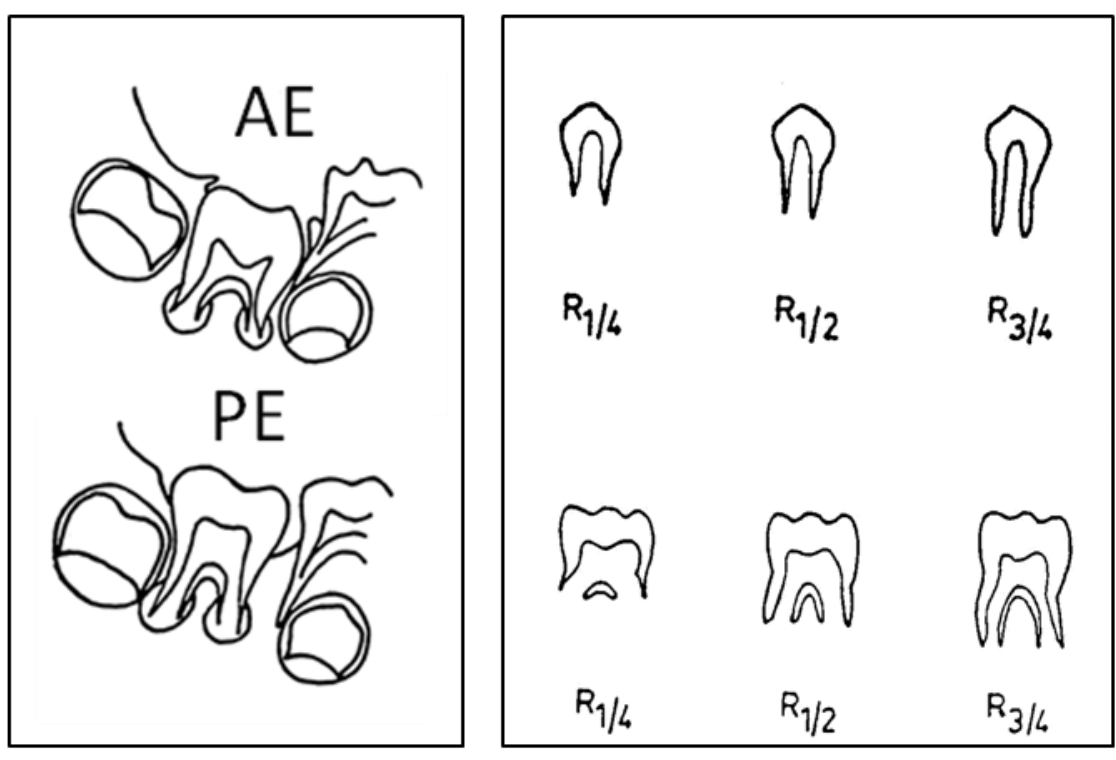

\section{Eruption stages and root fractions}

Fig. 1. Eruption levels and root fraction stages used in this study. A molar is shown at stages AE (alveolar eruption) and PE (partial eruption). Root fractions are from Haavikko (1970).

TABLE 1. Methods of age estimation from alveolar (AE) and partial (PE) stages of eruption of mandibular teeth used in this study ${ }^{1}$

\begin{tabular}{cccrrrrr}
\hline Tooth & Sex & $\begin{array}{c}\text { Gleiser }+ \text { Hunt } \\
\text { AE }\end{array}$ & $\begin{array}{c}\text { Garn } \\
\text { AE }\end{array}$ & $\begin{array}{c}\text { Ando } \\
\text { AE }\end{array}$ & $\begin{array}{c}\text { Haavikko } \\
\text { AE }\end{array}$ & $\begin{array}{r}\text { Haavikko } \\
\text { PE }\end{array}$ & $\begin{array}{c}\text { Smith } \\
\text { PE }\end{array}$ \\
\hline $\mathrm{I} 1$ & girls & & & 6.30 & $\mathbf{5 . 8}$ & $\mathbf{6 . 2}$ & $\mathbf{6 . 1 5}$ \\
& boys & & & 6.28 & $\mathbf{5 . 9}$ & $\mathbf{6 . 3}$ & $\mathbf{6 . 2 6}$ \\
$\mathrm{I} 2$ & girls & & & 7.13 & $\mathbf{6 . 5}$ & 6.8 & 7.24 \\
& boys & & & 7.14 & $\mathbf{6 . 9}$ & 7.3 & 7.47 \\
$\mathrm{C}$ & girls & & & 9.24 & 8.8 & 9.2 & 9.81 \\
& boys & & & 9.54 & 9.8 & 10.4 & 10.71 \\
$\mathrm{P} 1$ & girls & & $\mathbf{9 . 7}$ & 9.59 & 9.1 & 9.6 & 10.45 \\
& boys & & $\mathbf{1 0 . 1}$ & 9.61 & 9.6 & 10.3 & 10.89 \\
$\mathrm{P} 2$ & girls & & $\mathbf{1 0 . 3}$ & 10.46 & 9.2 & 10.1 & 11.62 \\
& boys & & $\mathbf{1 1 . 1}$ & 10.54 & 10.3 & 11.1 & 11.96 \\
$\mathrm{M} 1$ & girls & $\mathbf{5 . 1}$ & 5.7 & & $\mathbf{5 . 0}$ & 6.3 & 6.27 \\
& boys & $\mathbf{5 . 4}$ & 5.8 & & $\mathbf{5 . 3}$ & 6.3 & 6.32 \\
$\mathrm{M} 2$ & girls & & 10.7 & 10.86 & $\mathbf{9 . 9}$ & $\mathbf{1 1 . 4}$ & $\mathbf{1 1 . 5 8}$ \\
& boys & & 11.2 & 10.98 & $\mathbf{1 0 . 8}$ & $\mathbf{1 2 . 2}$ & $\mathbf{1 2 . 0 6}$ \\
\hline
\end{tabular}

${ }^{1}$ Methods include mean age from Gleiser and Hunt (1955), Garn et al. (1958), mean age calculated from Ando et al. (1965) tabulated in Liversidge (2003), median age from Haavikko (1970) and mean age of clinical emergence from Smith et al. (1998). Bold values estimated age with no average bias (difference between dental age and chronological age not significant to zero). 
compared to zero using a t-test with a significance level of $\mathrm{P}<0.05$. A method, tooth or eruption level was considered accurate if the difference was not significant to zero. The difference between chronological and estimated age for teeth at $\mathrm{AE}$ and $\mathrm{PE}$ was also split by root fractions and compared to zero if $\mathrm{N} \geq 10$ per tooth stage.

\section{RESULTS}

The number of erupting teeth (AE and/or PE) in the left side of the mandible within an individual ranged from zero to four. Just over half of this large sample $(52 \%)$ had one or more erupting teeth. This is a reflection of the age range of the sample with most of the youngest individuals having no permanent teeth erupted and most of the older individuals having all seven permanent teeth erupted. The most frequent number of erupt- ing teeth was one erupting tooth and only a small percentage of the sample had three or four erupting teeth.

Accuracy of estimating age from eruption levels showed that generally, early erupting teeth performed better than late erupting teeth. The difference between estimated and chronological age using the methods tested in this study for individual teeth are shown in Table 2. The difference for M1 at AE using Gleiser and Hunt was not significant to zero. The two premolars using Garn also estimated age accurately. No tooth using Ando performed well. Alveolar eruption of incisors and molars and partial eruption of I1 and M2 using Haavikko and Smith estimated age accurately. Most tooth types underestimated age with the canine and premolars considerably under-estimating age at both eruption levels.

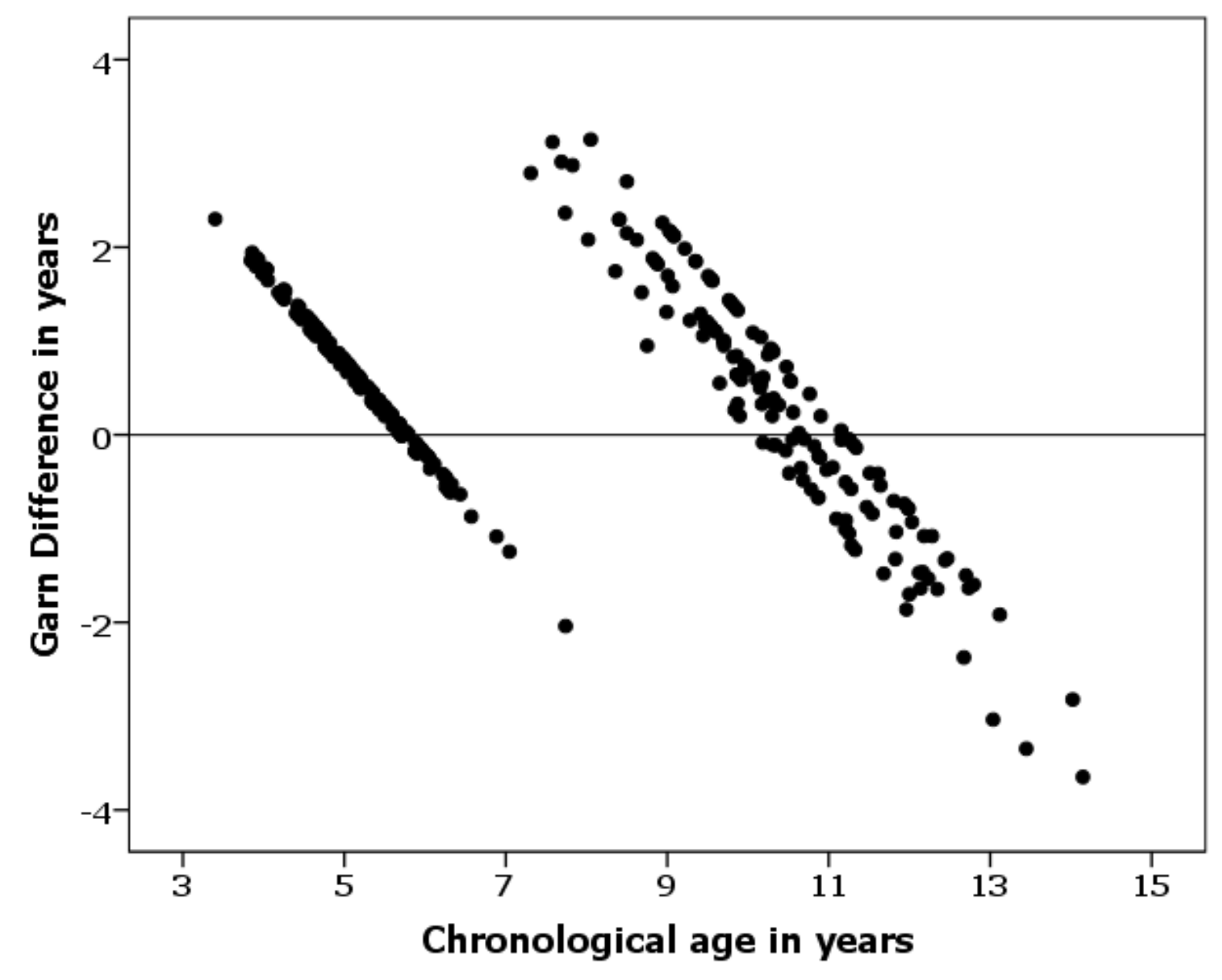

Fig. 2. Scatterplot of estimated age using Garn alveolar eruption and chronological age in years. 
TABLE 2. Accuracy of estimating age from alveolar eruption (AE) and partial eruption (PE) using methods of Gleiser and Hunt, Garn, Ando and Haavikko', and Smith

\begin{tabular}{|c|c|c|c|c|c|}
\hline $\begin{array}{c}\text { Method } \\
\text { Eruption level }\end{array}$ & Tooth & $\mathrm{N}$ & Mean difference & SD & $\mathrm{P}$ value \\
\hline \multicolumn{6}{|l|}{ Gleiser+Hunt } \\
\hline $\mathrm{AE}$ & M1 & 106 & 0.04 & 0.78 & 0.62 \\
\hline \multicolumn{6}{|l|}{ Garn } \\
\hline $\mathrm{AE}$ & P1 & 46 & -0.32 & 1.36 & 0.11 \\
\hline $\mathrm{AE}$ & $\mathrm{P} 2$ & 39 & -0.28 & 1.30 & 0.19 \\
\hline $\mathrm{AE}$ & M1 & 109 & 0.55 & 0.79 & $0.00 * *$ \\
\hline $\mathrm{AE}$ & M2 & 115 & 0.58 & 1.25 & $0.00 * *$ \\
\hline \multicolumn{6}{|l|}{ Ando } \\
\hline $\mathrm{AE}$ & I1 & 59 & 0.57 & 0.68 & $0.00 * *$ \\
\hline $\mathrm{AE}$ & $\mathrm{I} 2$ & 48 & 0.28 & 0.84 & $0.03 *$ \\
\hline $\mathrm{AE}$ & $\mathrm{C}$ & 36 & -0.91 & 1.10 & $0.00 * *$ \\
\hline $\mathrm{AE}$ & $\mathrm{P} 1$ & 46 & -0.69 & 1.32 & $0.00 * *$ \\
\hline $\mathrm{AE}$ & $\mathrm{P} 2$ & 39 & -0.42 & 1.29 & $0.05^{*}$ \\
\hline $\mathrm{AE}$ & M2 & 115 & 0.56 & 1.24 & $0.00 * *$ \\
\hline \multicolumn{6}{|l|}{ Haavikko } \\
\hline $\mathrm{AE}$ & I1 & 59 & 0.13 & 0.68 & 0.14 \\
\hline $\mathrm{AE}$ & $\mathrm{I} 2$ & 48 & -0.16 & 0.86 & 0.20 \\
\hline $\mathrm{AE}$ & $\mathrm{C}$ & 36 & -1.10 & 1.16 & $0.00 * *$ \\
\hline $\mathrm{AE}$ & $\mathrm{P} 1$ & 46 & -0.86 & 1.38 & $0.00 * *$ \\
\hline $\mathrm{AE}$ & $\mathrm{P} 2$ & 39 & -1.22 & 1.35 & $0.00 * *$ \\
\hline $\mathrm{AE}$ & M1 & 109 & -0.02 & 0.79 & 0.74 \\
\hline $\mathrm{AE}$ & M2 & 115 & -0.01 & 1.29 & 0.91 \\
\hline \multicolumn{6}{|l|}{ Haavikko } \\
\hline PE & I1 & 36 & -0.16 & 0.80 & 0.24 \\
\hline PE & $\mathrm{I} 2$ & 39 & -0.77 & 1.02 & $0.00 * *$ \\
\hline PE & $\mathrm{C}$ & 54 & -1.35 & 1.46 & $0.00 * *$ \\
\hline PE & $\mathrm{P} 1$ & 54 & -1.54 & 1.46 & $0.00 * *$ \\
\hline $\mathrm{PE}$ & $\mathrm{P} 2$ & 42 & -1.78 & 1.92 & $0.00 * *$ \\
\hline $\mathrm{PE}$ & M1 & 50 & 0.29 & 0.89 & $0.02 *$ \\
\hline PE & M2 & 42 & 0.02 & 1.39 & 0.92 \\
\hline \multicolumn{6}{|l|}{ Smith } \\
\hline $\mathrm{PE}$ & I1 & 36 & -0.21 & 0.80 & 0.13 \\
\hline PE & $\mathrm{I} 2$ & 39 & -0.45 & 1.00 & $0.00 * *$ \\
\hline $\mathrm{PE}$ & $\mathrm{C}$ & 54 & -0.95 & 1.59 & $0.00 * *$ \\
\hline PE & $\mathrm{P} 1$ & 54 & -1.12 & 1.82 & $0.00 * *$ \\
\hline PE & $\mathrm{P} 2$ & 42 & -0.87 & 2.02 & $0.01 * *$ \\
\hline $\mathrm{PE}$ & M1 & 50 & 0.30 & 0.88 & $0.02 *$ \\
\hline $\mathrm{PE}$ & M2 & 42 & 0.05 & 1.36 & 0.82 \\
\hline
\end{tabular}

${ }^{1} \mathrm{AE}$ and $\mathrm{PE}$ for individual teeth, ${ }^{*} \mathrm{P}<0.05, * * \mathrm{P}<0.01$. Mean difference $=$ estimated age minus chronological age in years. 
TABLE 3. Individual Haavikko root stages fractions and eruption levels where the average difference between estimated and chronological ages was not significantly different to zero (Mean difference in years, SD standard deviation in years)

\begin{tabular}{|c|c|c|c|c|c|c|c|}
\hline Tooth & Stage & Eruption & Method & $\mathrm{N}$ & Mean diff & $\mathrm{SD}$ & $\mathrm{P}$ value \\
\hline \multirow[t]{2}{*}{ I1 } & $\mathrm{R} 1 / 2$ & $\mathrm{AE}$ & Haavikko & 25 & 0.12 & 0.66 & 0.38 \\
\hline & $\mathrm{R} 3 / 4$ & $\mathrm{AE}$ & Ando & 10 & -0.03 & 0.57 & 0.86 \\
\hline \multirow[t]{3}{*}{$\mathrm{I} 2$} & $\mathrm{R} 1 / 2$ & $\mathrm{AE}$ & Haavikko & 25 & 0.09 & 0.73 & 0.53 \\
\hline & $\mathrm{R} 3 / 4$ & $\mathrm{AE}$ & Ando & 14 & -0.18 & 0.68 & 0.35 \\
\hline & $\mathrm{R} 3 / 4$ & $\mathrm{PE}$ & Smith & 20 & -0.06 & 0.55 & 0.65 \\
\hline \multirow[t]{2}{*}{$\mathrm{C}$} & $\mathrm{R} 3 / 4$ & PE & Haavikko & 14 & -0.44 & 1.19 & 0.19 \\
\hline & $\mathrm{R} 3 / 4$ & PE & Smith & 14 & -0.03 & 1.21 & 0.94 \\
\hline P1 & $\mathrm{R} 3 / 4$ & $\mathrm{PE}$ & Smith & 24 & -0.41 & 1.13 & 0.09 \\
\hline $\mathrm{P} 2$ & $\mathrm{R} 3 / 4$ & $\mathrm{PE}$ & Smith & 15 & 0.16 & 1.20 & 0.61 \\
\hline \multirow[t]{2}{*}{ M1 } & $\mathrm{R} 1 / 4$ & $\mathrm{AE}$ & Haavikko & 77 & 0.12 & 0.73 & 0.15 \\
\hline & $\mathrm{R} 1 / 2$ & $\mathrm{AE}$ & Garn & 28 & 0.10 & 0.73 & 0.46 \\
\hline \multirow[t]{3}{*}{ M2 } & $\mathrm{R} 1 / 2$ & $\mathrm{AE}$ & Haavikko & 41 & -0.30 & 1.04 & 0.07 \\
\hline & $\mathrm{R} 3 / 4$ & $\mathrm{PE}$ & Haavikko & 25 & 0.20 & 1.12 & 0.38 \\
\hline & $\mathrm{R} 3 / 4$ & $\mathrm{PE}$ & Smith & 25 & 0.19 & 1.05 & 0.38 \\
\hline
\end{tabular}

Standard deviation values were high for most teeth ranging from 0.68 to just over 2 years. The difference between estimated age using Garn and chronological age is plotted against chronological age in Figure 2. This shows the early (first molar) and late phases of erupting teeth (premolars and second molar) and the age variation for each phase. The zero line indicates individuals whose teeth erupt at average age. Age is overestimated for individuals whose teeth are advanced in eruption and underestimated for individuals whose teeth are delayed in eruption.

Further analyses by Haavikko tooth stage are shown Table 3 with only combinations of root fraction and eruption level with differences not significantly different to zero reported. For both incisors at $\mathrm{AE}$ and root stage R1/2 Haavikko and R3/4 Ando estimated age accurately. Haavikko estimated age accurately (not significant to zero) if $\mathrm{M} 1$ was at $\mathrm{AE}$ and R1/4, but if root stage was R1/2 then Garn estimated age accurately. Two teeth estimated age accurately at PE (Haavikko): the canine and M2 at R3/4. If M2 was $\mathrm{AE}$ and R1/2, Haaviko estimated age accurately.

The results of accuracy comparing tooth stage and eruption level using Haavikko root fractions for teeth at AE and PE are shown in Table 4. There were four combinations of eruption level and tooth stage that accurately estimated age using Haavikko (I1 at AE and R1/2, M1 at AE and R1/4, $\mathrm{M} 2$ at $\mathrm{AE}$ and R1/2 and M2 at PE and R3/4). For all these combinations, the estimated age from root stage was closer to chronological age than estimated age from eruption level. Standard variation for M2 stages were considerably greater than earlier erupting teeth.

\section{DISCUSSION}

Tooth eruption has long been thought to be more variable than tooth formation and therefore less accurate at estimating age. Our results show that alveolar eruption and partial eruption (including gingival emergence into the oral cavity) of permanent mandibular teeth can be used to estimate age in the immature dentition when root stage cannot be seen or has been damaged. Alveolar eruption of early erupting permanent teeth ( I1, I2 and M1) as well as both AE and PE eruption levels of M2 can estimate age accurately.

The finding that Gleiser and Hunt and Haavikko values of M1 AE could accurately estimate age suggests that there has been no secular change in the eruption process of this tooth.

The use of gingival eruption of individual 
teeth to estimate age should be interpreted as a minimum age. The position of the cusp tips of a recently erupted tooth in the oral cavity relative to the occlusal level is not well documented and is influenced by local factors and tooth type. Molars probably erupt closer to the occlusal level than later erupting premolars and canines.

The strength of this study was the large sample age range with sufficient individuals prior to AE of M1 as well as sufficient older individuals. These older children, however, were drawn from orthodontic clinics and several individuals were excluded because they appeared to have crowding of teeth that prevented full eruption. Limitations of this study include the definition of partial eruption. Dean (2007) defined erupted stage more carefully with early and late eruption with cusp tips at/below the maximum bulbosity of the adjacent crown. Assessing the process of tooth eruption into our discrete stages appeared to have adequate reproducibility. Further research is needed to assess if our partial eruption level is equivalent to clinical emergence.

\section{CONCLUSIONS}

The eruption of mandibular permanent teeth can play a role in estimating age. Accuracy is higher using early erupting permanent teeth I (M1 and incisors) to estimate age compared to later erupting teeth. Gleiser and Hunt for M1 AE and Haavikko I1, I2 and M1 and M2 AE and I1, M2 at PE are recommended to estimate age. If a tooth is erupting and root stage can be assessed, accuracy is higher using root stage.

\section{ACKNOWLEDGEMENTS}

The first author received funding from Barts and The London School of Medicine and Dentistry for a summer vacation studentship prior to completing her dental degree.

\section{LITERATURE CITED}

AlQahtani SJ, Hector MP, Liversidge HM. 2014. Accuracy of dental age estimation charts: Schour and Massler, Ubelaker and the London Atlas. Am J Phys Anthropol 154:70-78.

Ando S, Aizawa K, Nakashima T, Shinbo K, Sanka

Y, Kiyokawa K, Oshima S. 1965. Studies on the consecutive survey of succedaneous and permanent dentition in the Japanese children. I: Eruption processes of permanent teeth. J Nihon Univ School Dent 7:141-181.

Dean MC. 2007. A radiographic and histological study of modern human lower first permanent molar root growth during the supraosseous eruptive phase. J Hum Evol 53:635-46.

Garn, SM Lewis AB. 1957. Relationship between the sequence of calcification and the sequence of eruption of the mandibular molar and premolar teeth. J Dent Res 36:992-995.

Garn SM, Lewis AB, Koski K, Polacheck DL. 1958. The sex difference in tooth calcification. J Dent Res 37:561-7.

Gleiser I, Hunt EE. 1955. The permanent mandibular first molar: its calcification, eruption and decay. Am J Phys Anthropol 13:253-283.

TABLE 4. A comparison of accuracy estimating age from eruption level and tooth stage using Haavikko ${ }^{1}$

\begin{tabular}{ccccccc}
\hline Tooth & $\mathrm{N}$ & $\begin{array}{c}\text { Tooth } \\
\text { stage }\end{array}$ & $\begin{array}{c}\text { eruption } \\
\text { level }\end{array}$ & $\begin{array}{c}\text { Estimated age } \\
\text { method }\end{array}$ & $\begin{array}{c}\text { Mean } \\
\text { difference }\end{array}$ & SD \\
\hline $\mathrm{I} 1$ & 25 & $\mathrm{R} 1 / 2$ & $\mathrm{AE}$ & eruption & 0.12 & 0.66 \\
& 25 & $\mathrm{R} 1 / 2$ & $\mathrm{AE}$ & tooth stage & -0.03 & 0.68 \\
$\mathrm{M} 1$ & 77 & $\mathrm{R} 1 / 4$ & $\mathrm{AE}$ & eruption & 0.12 & 0.73 \\
& 77 & $\mathrm{R} 1 / 4$ & $\mathrm{AE}$ & tooth stage & 0.06 & 0.74 \\
$\mathrm{M} 2$ & 41 & $\mathrm{R} 1 / 2$ & $\mathrm{AE}$ & eruption & -0.31 & 1.04 \\
& 41 & $\mathrm{R} 1 / 2$ & $\mathrm{AE}$ & tooth stage & 0.03 & 1.27 \\
$\mathrm{M} 2$ & 25 & $\mathrm{R} 3 / 4$ & $\mathrm{PE}$ & eruption & 0.20 & 1.12 \\
& 25 & $\mathrm{R} 3 / 4$ & $\mathrm{PE}$ & tooth stage & 0.04 & 1.25 \\
\hline
\end{tabular}

1There were four combinations of eruption level and tooth stage that accurately estimated age using Haavikko (I1 at AE and R1/2, M1 at AE and R1/4, M2 at AE and R1/2 and M2 at PE and R3/4). For all these combinations, the estimated age from the root stage was closer to chronological age than estimated age from eruption level. 
Haavikko K. 1970. The formation and the alveolar and clinical eruption of the permanent teeth: an orthopantomographic study. Proc Finn Dent Soc 66:103-170.

Hassanali J, Odhiambo JW. 1982. Estimation of calendar age from eruption times of permanent teeth in Kenyan Africans and Asians. Ann Hum Biol 9:175-177.

Liversidge HM. 2003. Worldwide variation in human dental development. In: Thompson JL, Nelson A, Krovitz G, editors. Growth and Develop ment in the Genus Homo. Cambridge: Cambridge University Press. p 73-113.

Liversidge HM, Smith BH, Maber M. 2010. Bias and accuracy of age estimation using developing teeth in 946 children. Am J Phy Anthropol 143:545-554.
Maber M, Liversidge HM, Hector MP. 2006. Accuracy of age estimation of radiographic methods using developing teeth. Forensic Sci Intl 159:S68573.

Miles AEW. 1963, Dentition in the estimation of age. J Dent Res 42:255-63.

Moorrees CFA, Fanning EA, Hunt EE. 1963. Age variation of formation stages for ten permanent teeth. J Dent Res 42:1490-1502.

Smith JM, Smith RN, Brook AH, Elcock C. 1998. Timing of permanent tooth eruption in London School children. In: Mayall JT, Heikkinen T, editors. Dental Morphology '98. Oulu, Finland: Oulu University Press. p 187-191. 